\title{
Cytokine profile and pathology in human leishmaniasis
}

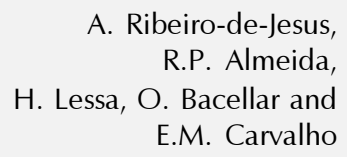

A. Ribeiro-de-Jesus, R.P. Almeida, H. Lessa, O. Bacellar and E.M. Carvalho

Serviço de Imunologia, Hospital Universitário Prof. Edgard Santos, Universidade Federal da Bahia, Salvador, BA, Brasil

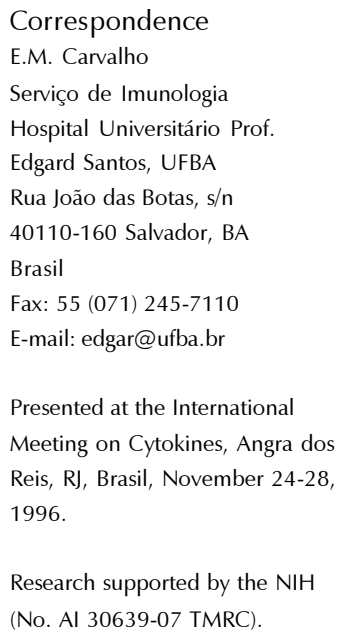

\section{Abstract}

The clinical spectrum of leishmaniasis and control of the infection are influenced by the parasite-host relationship. The role of cellular immune responses of the Th1 type in the protection against disease in experimental and human leishmaniasis is well established. In humans, production of IFN- $\gamma$ is associated with the control of infection in children infected by Leishmania chagasi. In visceral leishmaniasis, an impairment in IFN- $\gamma$ production and high IL-4 and IL-10 levels (Th2 cytokines) are observed in antigen-stimulated peripheral blood mononuclear cells (PBMC). Moreover, IL-12 restores IFN- $\gamma$ production and enhances the cytotoxic response. IL-10 is the cytokine involved in down-regulation of IFN- $\gamma$ production, since anti-IL-10 monoclonal antibody $(\mathrm{mAb})$ restores in vitro IFN- $\gamma$ production and lymphoproliferative responses, and IL-10 abrogates the effect of IL-12. In cutaneous and mucosal leishmaniasis, high levels of IFN- $\gamma$ are found in L. amazonensis-stimulated PBMC. However, low or absent IFN- $\gamma$ levels were observed in antigen-stimulated PBMC from 50\% of subjects with less than 60 days of disease $(24 \pm 26 \mathrm{pg} / \mathrm{ml})$. This response was restored by IL-12 $(308 \pm 342 \mathrm{pg} / \mathrm{ml})$ and anti-IL-10 $\mathrm{mAb}(380 \pm 245$ $\mathrm{pg} / \mathrm{ml})(\mathrm{P}<0.05)$. Later during the disease, high levels of IFN- $\gamma$ and TNF- $\alpha$ are produced both in cutaneous and mucosal leishmaniasis. After treatment there is a decrease in TNF- $\alpha$ levels $(366 \pm 224 \mathrm{pg} / \mathrm{ml}$ before treatment vs $142 \pm 107 \mathrm{pg} / \mathrm{ml}$ after treatment, $\mathrm{P}=0.02$ ). Although production of IFN- $\gamma$ and TNF- $\alpha$ might be involved in the control of parasite multiplication in the early phases of Leishmania infection, these cytokines might also be involved in the tissue damage seen in tegumentary leishmaniasis.

Leishmaniasis is a parasitic infection caused by a protozoan from the Trypanosomatidae family, genus Leishmania. Four clinical forms of the disease have been described: visceral, cutaneous, mucosal and diffuse cutaneous leishmaniasis $(1,2)$. This clinical spectrum of the disease is mostly related to different Leishmania species (1-5), but the immunological responses to the parasite are certainly an important determinant of the
Key words

- Leishmaniasis

- Human leishmaniasis

- Cytokines

- Pathology

- Immunological responses clinical outcome of Leishmania infection (6). For instance, it has been demonstrated that the prevalence of serological conversion in an endemic area of visceral leishmaniasis is higher than the prevalence of disease (7). This finding suggests that there are subjects that are infected and can control the disease. It is known from studies on experimental models of leishmaniasis that the control of Leishmania infection is dependent on $\mathrm{T}$ cell 
responses. The role of Th1 or Th 2 cell activation in determining resistance and susceptibility to leishmaniasis has been well demonstrated in two experimental hosts: the susceptible $\mathrm{BALB} / \mathrm{c}$ mouse and the resistant $\mathrm{C} 3 \mathrm{H} / \mathrm{HeN}$ mouse infected with L. major (810). While BALB/c mice develop a Th2 response after infection with $\mathrm{L}$. major and have severe and progressive disease, $\mathrm{C} 3 \mathrm{H} /$ HeN mice develop a Th1 type of response, with interferon-gamma (IFN- $\gamma$ ) production, are able to control Leishmania multiplication and have a self-limited disease (10). In these animals, treatment with anti-IL-4 monoclonal antibody $(\mathrm{mAb})$ at the time of infection makes $\mathrm{BALB} / \mathrm{c}$ mice able to control leishmaniasis (11) while treatment of $\mathrm{C} 3 \mathrm{H} /$ $\mathrm{HeN}$ animals with anti-IFN- $\gamma \mathrm{mAb}$ is associated with progression of the infection and severe disease (12). In humans, the strongest evidence that production of IFN- $\gamma$ is involved in the control ofLeishmania infection comes from a longitudinal study evaluating lymphoproliferative response and IFN- $\gamma$ production by peripheral blood mononuclear cells (PBMC) from serum-converting children from an endemic area of visceral leishmaniasis. In that study, it was demonstrated that, upon Leishmania chagasi infection, children whose Leishmania antigen-stimulated PBMC produce IFN- $\gamma$ will control the infection, while children who have a poor IFN- $\gamma$ production will progress to visceral leishmaniasis (13). These observations clearly indicate that absence or poor IFN- $\gamma$ production is a marker of susceptibility to visceral leishmaniasis. Although it is likely that several mechanisms may participate in the inability of lymphocytes from visceral leishmaniasis patients to produce this cytokine, one important point is related to the imbalance of cytokines produced in response to Leishmania antigens, i.e., high production of IL-4 and IL-10 and low IL-2 and IFN- $\gamma$ production (14-18). Although lymphocytes from patients with visceral leishmaniasis have a strong expression of mRNA for IL-4 $(16,18)$ and sera from visceral leishmaniasis patients have high IL-4 levels (14), there is no evidence that IL-4 is involved in the downregulation of the Th1 type of response in human leishmaniasis. For instance, in vitro addition of $m A b$ against IL-4 did not restore the lymphocyte proliferative response or IFN$\gamma$ production in L. chagasi-stimulated PBMC from visceral leishmaniasis patients (18). Interleukin-4 also did not suppress lymphocyte proliferative response or IFN- $\gamma$ production in subjects cured of leishmaniasis. Patients with visceral leishmaniasis have increased expression of mRNA for IL-10 in bone marrow and lymph node cells and high levels of IL-10 in L. chagasi-stimulated PBMC supernatants $(15,16,18)$. Moreover, the addition of $\mathrm{mAb}$ to anti-IL-10 restores lymphocyte proliferative response and IFN$\gamma$ production in PBMC from visceral leishmaniasis patients $(15,18)$. In visceral leishmaniasis, there is also an inability of PBMC to produce IL-12 (19) and restoration of IFN- $\gamma$ production and lymphocyte proliferative response can be achieved by IL-12 addition $(19,20)$. IL-12 also enhances the cytotoxic response, a function that is suppressed in visceral leishmaniasis patients (20). The demonstration that IL-10 abrogates the effect of IL-12 in inducing IFN- $\gamma$ production in L. chagasi-stimulated PBMC from visceral leishmaniasis patients strongly suggests that IL-10 is the major cytokine involved in the progression of Leishmania infection to visceral disease (20). Interleukin-10 blocks Th1 activation and consequently a cytotoxic response by down-regulating IL-12 and IFN- $\gamma$ production. Additionally, since IL-10 also inhibits macrophage activation (21) it decreases the ability of these cells to kill Leishmania.

In contrast to visceral leishmaniasis, patients with cutaneous and mucosal leishmaniasis due to L. braziliensis infection have a strong $\mathrm{T}$ cell response, characterized by a high lymphocyte proliferative response to Leishmania antigens and IFN- $\gamma$ production 
(22-25). Delayed-type hypersensitivity to Leishmania antigen is also present in these patients and the intradermal skin test is usually employed for the diagnosis of cutaneous and mucosal leishmaniasis. Since IFN- $\gamma$, a major cytokine associated with Leishmania killing, is produced during L. braziliensis infection, the reasons why such patients develop disease are not clear. The possibility that immunological responses may be altered in such patients at the site of the lesion is usually considered. However, immunological studies in cells from tissues of leishmaniasis patients have shown an immune response pattern similar to that seen in PBMC, with evidence of a Th0 or Th1/Th2 mixed cytokine pattern $(26,27)$. Some differences were found in the cytokine profile when patients with lesions of short duration were compared with those with old lesions. Patients with chronic lesions show a strong expression of pro-inflammatory cytokines such as TNF- $\alpha$ (28). Since the cytokines secreted in the early phases of infection in the experimental models of leishmaniasis are important to determine the progression or control of the infection, we hypothesize that alterations in the immunological responses early in human infection may account for parasite multiplication and for clinical outcome of the disease. In fact, we have previously shown that early in the infection (less than 60 days of disease) patients with cutaneous leishmaniasis may present a decrease in IFN- $\gamma$ production and an increase in IL-10 production when compared with patients with more than two months of disease (29). More recently, we have observed that absent or low IFN- $\gamma$ production may occur in up to $50 \%$ of the patients with early cutaneous leishmaniasis. To determine the role of cytokines in modulating the immune response in such patients, PBMC were stimulated with $\mathrm{L}$. amazonensis antigen in the presence of IL-12, anti-IL-4 mAb, and antiIL-10 mAb. IFN- $\gamma$ levels were determined by a sandwich ELISA technique in the cul- ture supernatants. In patients with early cutaneous leishmaniasis who did not have a $\mathrm{T}$ cell response to Leishmania antigen, the mean IFN- $\gamma$ level in L. amazonensis-stimulated PBMC supernatants was $24 \pm 26 \mathrm{pg} /$ $\mathrm{ml}$. While the addition of anti-IL-4 mAb did not enhance IFN- $\gamma$ production $(48 \pm 79 \mathrm{pg}$ / $\mathrm{ml}$ ), the addition of anti-IL-10 mAb or of IL12 enhanced IFN- $\gamma$ production to $380 \pm 245$ and $308 \pm 342 \mathrm{pg} / \mathrm{ml}$, respectively $(\mathrm{P}<0.05$, Mann-Whitney test).

The down-regulation of the immune response in cutaneous leishmaniasis is a transitory phenomenon since virtually all patients with more than 60 days of history of cutaneous ulcers present strong IFN- $\gamma$ production. Although this down-regulation of IFN- $\gamma$ production in the early phases of cutaneous leishmaniasis may account for parasite multiplication, we have no evidence that patients who had low IFN- $\gamma$ production will have a more severe disease measured by an increase in ulcer size or in the number of lesions, or dissemination of the infection. In contrast, preliminary data from a retrospective study show that the response to pentavalent antimonial therapy was better in patients with low IFN- $\gamma$ production than in patients with high IFN- $\gamma$ production. A more careful analysis of this observation is being performed in a prospective study with a larger number of patients. However, these preliminary data suggest that, although IFN- $\gamma$ is important for the control of parasite multiplication, it can also be involved in the pathogenesis of the disease. One possibility is that IFN- $\gamma$, by up-regulating TNF- $\alpha$ production, may lead this pro-inflammatory cytokine to participate in the tissue damage observed in tegumentary leishmaniasis. In fact, TNF- $\alpha$ levels are elevated in tegumentary leishmaniasis, mainly in the severe cutaneous and mucosal diseases $(30,31)$. In addition, serum TNF- $\alpha$ levels drop after therapy of mucosal leishmaniasis (31).

To evaluate the role of TNF- $\alpha$ in the pathology of tegumentary leishmaniasis, we 
determined TNF- $\alpha$ levels in PBMC supernatants from patients with classical cutaneous and mucosal leishmaniasis, before and after therapy. The TNF- $\alpha$ and IFN- $\gamma$ levels of patients with classical cutaneous leishmaniasis and mucosal disease are shown in Figure 1. Both IFN- $\gamma$ and TNF- $\alpha$ were elevated in L. amazonensis-stimulated PBMC from patients with cutaneous and mucosal leishmaniasis. After successful therapy there was a reduction in both IFN- $\gamma$ and TNF- $\alpha$ levels in $42 \%$ and $72 \%$ of the patients, respectively. A significant reduction in TNF- $\alpha$ levels was observed after successful therapy $(366 \pm 224 \mathrm{pg} / \mathrm{ml}$ before therapy vs $142 \pm$

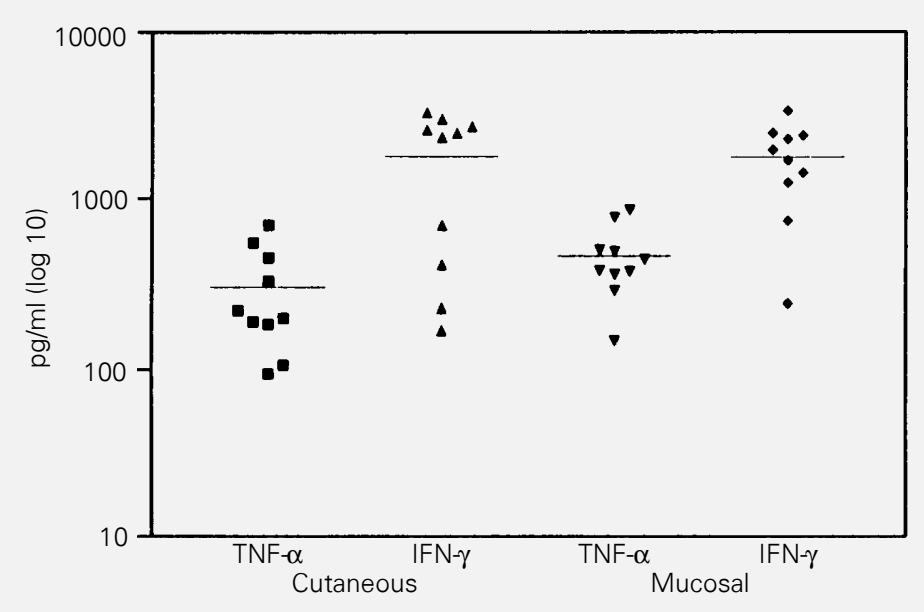

Figure 1 - TNF- $\alpha$ and IFN- $\gamma$ levels in Leishmania antigen-stimulated PBMC from patients with cutaneous and mucosal leishmaniasis.

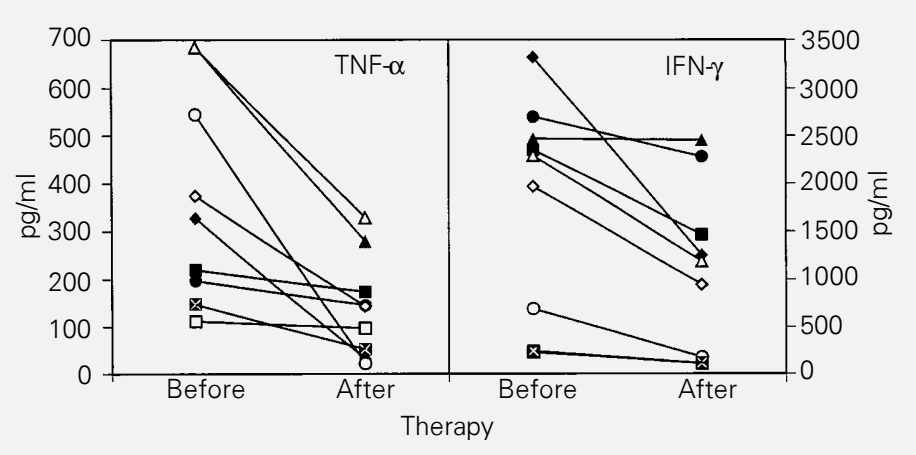

Figure 2 - TNF- $\alpha$ and IFN- $\gamma$ levels in Leishmania antigen-stimulated PBMC before and after therapy in patients with tegumentary leishmaniasis. $P=0.02$ for TNF- $\alpha$ levels before and after treatment (Mann-Whitney test). Different symbols represent the patients.
$107 \mathrm{pg} / \mathrm{ml}$ after therapy, $\mathrm{P}=0.02$, MannWhitney test) (Figure 2).

Finally, to determine if by decreasing TNF- $\alpha$ levels it is possible to improve the healing of mucosal leishmaniasis lesions, we are performing an open study evaluating the efficacy of pentoxifylline associated with antimonial therapy in patients with mucosal lesions refractory to antimonial therapy. Pentoxifylline is an aminoxanthine that has the ability to decrease mRNA for TNF- $\alpha$ and consequently decreases TNF- $\alpha$ production $(32,33)$. A pilot study with 6 patients with active mucosal disease who had received at least two courses of antimonial therapy (20 $\mathrm{mg} \mathrm{kg}^{-1}$ day $^{-1}$ for 20 days) before entering the study was performed. The mean age of the patients ( 5 men, 1 woman) was $24 \pm 12$ years. These patients received a new course of pentavalent antimony (Glucantime Rhodia, $20 \mathrm{mg} / \mathrm{kg}$ body weight) associated with pentoxifylline ( $1.2 \mathrm{~g} /$ day for 20 days). The patients were evaluated every 30 days up to 3 months and 6 and 12 months after the end of therapy. The lesions of all patients who received the antimonial therapy associated with pentoxifylline healed after 30 to 60 days of therapy.

Several lines of evidence show that IFN$\gamma$ and TNF- $\alpha$ are important for the control of leishmaniasis. TNF- $\alpha$ plays an important protective role in experimental murine cutaneous leishmaniasis (34-36) and synergizes with IFN- $\gamma$ in mediating killing of Leishmania major through the induction of nitric oxide (34). In human visceral leishmaniasis and diffuse cutaneous leishmaniasis there is evidence that the absence of IFN- $\gamma$ allows parasite multiplication and progression from infection to disease $(13,29)$. It is also expected that $\mathrm{T}$ cell responses and monocyte function are important in the control of $\mathrm{L}$. braziliensis infection. In fact, there is evidence of a Th1 type of response in subjects with subclinical L. braziliensis infection and in subjects with self-healing cutaneous leishmaniasis (37). The observation presented 
here that, early in the infection, $\mathrm{T}$ cell response is depressed in cutaneous leishmaniasis may indicate that, after infection, there is an absence of IFN- $\gamma$ production that allows parasite multiplication. Later on, there is production of IFN- $\gamma$ that may control the infection. However, an exacerbated production of IFN- $\gamma$ and TNF- $\alpha$ can be deleterious for the tissue. Therefore, the present data indicate that the same cytokines involved in parasite killing may also be involved in the pathogenesis of cutaneous and mucosal leishmaniasis.

\section{Acknowledgments}

\section{We thank Ednaldo Lago for his dedicated} work in the endemic area of Corte de Pedra, and Jackson Lemos and Maria das Graças Bueno for secretarial assistance.

\section{References}

1. Lainson R \& Shaw JJ (1978). Epidemiology and ecology of leishmaniasis in LatinAmerica. Nature, 273: 595-600

2. Marsden PD (1979). Current concepts in parasitology. Leishmaniasis. New England Journal of Medicine, 300: 350-352.

3. Barral A, Pedral-Sampaio D, Grimaldi G, Momen $\mathrm{H}$, McMahon-Pratt $\mathrm{D}$, Ribeiro de Jesus A, Almeida R, Badaró R, BarralNetto M, Carvalho EM \& Johnson WD (1991). Leishmaniasis in Bahia, Brazil: Evidence that Leishmania amazonensis produces a wide spectrum of clinical disease. American Journal of Tropical Medicine and Hygiene, 44: 536-546.

4. Grimaldi GJ, David JR \& McMahon PD (1987). Identification and distribution of New World Leishmania species characterized by serodeme analysis using monoclonal antibodies [published erratum appears in American Journal of Tropical Medicine and Hygiene, 37: 414, 1987]. American Journal of Tropical Medicine and Hygiene, 36: 270-287.

5. Grimaldi GJ, Momen H, Naiff RD, McMahon PD \& Barrett TV (1991). Characterization and classification of leishmanial parasites from humans, wild mammals, and sand flies in the Amazon region of Brazil. American Journal of Tropical Medicine and Hygiene, 44: 645-661.

6. Convit J, Pinardi ME \& Randon AJ (1972). Diffuse cutaneous leishmaniasis: A disease due to an immunological defect of the host. Transactions of the Royal Society of Tropical Medicine and Hygiene, 66: 603-610

7. Badaró R, Carvalho EM, Rocha H, Queiroz AC \& Jones TC (1986). Leishmania donovani: An opportunistic microbe associated with progressive disease in three immunocompromised patients. Lancet, 1: 647648.

8. Scott $P$ (1991). Interferon gamma modu- lates the early development of Th1 and Th2 responses in a murine model of cutaneous leishmaniasis. Journal of Immunology, 147: 3149-3155.

9. Heinzel FP, Sadick MD, Holaday RL, Coffman RL \& Locksley RM (1989). Reciprocal expression of IFN- $\gamma$ or IL-4 during the resolution or progression of murine leishmaniasis. Evidence for expression of distinct helper T cell subsets. Journal of Experimental Medicine, 169: 59-72.

10. Heinzel FP, Sadick MD, Mutha SS \& Locksley RM (1991). Production of IFN- $\gamma$, IL-2, IL-4 and IL-10 by CD4+ lymphocytes in vivo during healing and progressive murine leishmaniasis. Proceedings of the National Academy of Sciences, USA, 80: 7011-7015.

11. Chatelain $R$, Varkila $K$ \& Coffman $R L$ (1992). Interleukin-4 induces a Th2 response in L. majorinfected mice. Journal of Immunology, 148: 1182-1187.

12. Belosevic M, Finbloom DS, Van Der Meide PH, Slayter MV \& Nacy CA (1989). Administration of monoclonal anti IFN- $\gamma$ antibodies in vivo abrogates natural resistance of $\mathrm{C} 3 \mathrm{H} / \mathrm{NeN}$ mice to infection with Leishmania major. Journal of Immunology, 143: 266-271.

13. Carvalho EM, Barral A, Pedral-Sampaio D, Barral-Netto $M$, Badaró $R$, Rocha $H$ \& Johnson WD (1992). Immunologic markers of clinical evolution in children recently infected with $L$. donovani chagasi. Journal of Infectious Diseases, 165: 535-540.

14. Zwingenberger K, Harms G, Pedrosa C, Omena S, Sandkamp B \& Neifer S (1990). Determinants of the immune response in visceral leishmaniasis: evidence for predominance of endogenous interleukin 4 over interferon- $\gamma$ production. Clinical Immunology and Immunopathology, 57: 242-249.

15. Ghalib HW, Piuvezam MR, Sheiky $Y$,
Siddig M, Hashim FA, El Hassan AM, Russo DM \& Reed SG (1993). Interleukin10 production correlates with pathology in human Leishmania donovani infections. Journal of Clinical Investigation, 92: 324329

16. Karp CL, El Safi SH, Wynn TA, Satti MM Kordofani AM, Hashim FA, Hag-Ali M, Neva FA, Nutman TB \& Sacks DL (1993). In vivo cytokine profiles in patients with kala-azar. Journal of Clinical Investigation, 91: 1644-1648.

17. Holaday BJ, Pompeu MM, Jeronimo S, Teixeira MJ \& Sousa A de A (1993). Potential role for IL-10 in the immune suppression associated with kala-azar. Journal of Clinical Investigation, 92: 26262632

18. Carvalho EM, Bacellar O, Brownell C Regis T, Coffman RL \& Reed SG (1994). Restoration of IFN- $\gamma$ production and lymphocyte proliferation in visceral leishmaniasis. Journal of Immunology, 152: 5949-5956

19. Ghalib HW, Whitle JA, Kubim M, Hashim FA, El-Hassan BM, Grabstein G, Trinchier: G \& Reed SG (1995). Interleukin-12 enhances Th1 type immune response in human Leishmania donovani infection. Journal of Immunology, 154: 4623-4629.

20. Bacellar O, Brodskyn C, Guerreiro J Barral-Netto M, Costa CH, Coffman RL, Johnson WD \& Carvalho EM (1996). Interleukin-12 restores interferon- $\gamma$ production and cytotoxic responses in visceral leishmaniasis. Journal of Infectious Diseases, 173: 1515-1518.

21. Bogdan C, Vodovotz Y \& Nathan C (1991). Macrophage deactivation by IL-10. Journal of Experimental Medicine, 174: 15491560

22. Castés M, Agnelli $A$, Verde $O$ \& Rondon AJ (1983). Characterization of the cellular immune response in American cutaneous 
Ieishmaniasis. Clinical Immunology and Immunopathology, 27: 176-186.

23. Carvalho EM, Johnson WD, Barreto $E$, Marsden PD, Costa JML, Reed S \& Rocha $H$ (1985). Cell mediated immunity in American cutaneous and mucosal leishmaniasis. Journal of Immunology, 135: 4144-4148.

24. Coutinho SG, Pirmez C, Mendonça SCF, Conceição-Silva F \& Doréa RCC (1987). Pathogenesis and immunopathology of leishmaniasis. Memórias do Instituto Oswaldo Cruz, 82 (Suppl I): 214-228.

25. Mendonça SCF, Coutinho SG, Amendoeira MRR, Marzochi MCA \& Pirmez C (1986). Human American cutaneous leishmaniasis (Leishmania braziliensis braziliensis) in Brazil: lymphoproliferative response and influence of therapy. Clinical and Experimental Immunology, 64: 269-275

26. Pirmez C, Yamamura M, Uyemura K, Paes-Oliveira $M$, Conceição-Silva $F$ \& Modlin RL (1993). Cytokine patterns in the pathogenesis of human leishmaniasis. Journal of Clinical Investigation, 91: 1390-1395.

27. Cáceres-Dittmar G, Tapia FJ, Sanchez MA, Yamamura M, Uyemura K, Modlin RL, Bloom BR \& Convit J (1993). Determination of the cytokine profile in American cutaneous leishmaniasis using polymerase chain reaction. Clinical and Experimental Immunology, 91: 500-505.

28. Melby PC, Andrade Narvaez FJ, Darnell BJ, Balencia Pacheco G, Tryon VV \& Palomo-Cetina A (1994). Increased expression of pro-inflammatory cytokines in chronic lesions of human cutaneous leishmaniasis. Infection and Immunity, 62: 837-842.

29. Almeida RP, Rocha P, Jesus AR, Costa J \& Carvalho EM (1995). Evaluation of cellular immune responses in patients with different clinical forms of tegumentary leishmaniasis. Allergy Journal of Immunology, 14: 11-19.

30. Castés M, Trujillo D, Rojas ME, Fernandez CT, Araya L, Cabrera M, Blackwell J \& Convit J (1993). Serum levels of tumor necrosis factor in patients with American cutaneous leishmaniasis. Biological Research, 26: 233-238.

31. Da-Cruz AM, de-Oliveira MP, De-Luca PM, Mendonça SC \& Coutinho SG (1996). Tumor necrosis factor-alpha in human American tegumentary leishmaniasis. Memórias do Instituto Oswaldo Cruz, 91 225-229.

32. Strieter RM, Remick DG, Ward PA, Spengler RN, Lynch JP, Larrich J \& Kunkel SL (1988). Cellular and molecular regula- tion of tumor necrosis factor-alpha production by pentoxifylline. Biochemical and Biophysical Research Communications, 153: 1230-1236.

33. Doherty GM, Jensen JC, Alexander HR, Buresh CM \& Norton JA (1991). Pentoxifylline suppression of tumor necrosis factor gene transcription. Surgery, 110: 192198.

34. Liew FY, Li Y \& Millott S (1990). Tumor necrosis factor $\alpha$ synergizes with IFN- $\gamma$ in mediating killing of Leishmania major through the induction of nitric oxide. Journal of Immunology, 145: 4306-4310.

35. Liew FY, Parkinson C, Millott S, Severn A \& Carrier M (1990). Tumor necrosis factor (TNF- $\alpha$ ) in leishmaniasis. I. TNF- $\alpha$ mediates host protection against cutaneous leishmaniasis. Immunology, 69: 570-573.

36. Titus RG, Sherry B \& Cerami A (1989). Tumor necrosis factor plays a protective role in experimental murine cutaneous leishmaniasis. Journal of Experimental Medicine, 170: 2097-2104.

37. Carvalho EM, Correia Filho D, Bacellar O, Lessa H \& Rocha H (1995). Characterization of the immune response in subjects with self healing cutaneous leishmaniasis. American Journal of Tropical Medicine and Hygiene, 53: 273-277. 